\title{
LINHA EVOLUTIVA DA TEORIA TRIDIMENSIONAL DO DIREITO*
}

\author{
Miguel Reale \\ Professor Emérito da Faculdade de Direito da Universidade de São Paulo
}

\begin{abstract}
Resumo:
\end{abstract}
$\mathrm{O}$ artigo trata inicialmente das fontes que inspiraram a Teoria Tridimensional do Direito, das versões dos mestres italianos Icilio Vanni, Giorgio Del Vecchio e Adolfo Nová e da pergunta nascida nos bancos acadêmicos sobre problema essencial relativo à estrutura da experiência jurídica, da necessidade de se ir além de uma discriminação metodológica para se alcançar a realidade jurídica em si.

Em seguida, faz a crítica da visão kelseniana do Direito concebido como uma simples norma, além de um breve histórico da evolução da noção de Estrutura Tridimensional e da dialeticidade dos três elementos e suas conseqüências: fato - valor - norma; norma - valor - fato; norma - fato - valor.

Passa a abordar, a seguir, a temática da influência da fenomenologia de Husserl e a questão da Lebenswelt no seu pensamento, da dialética existencial do Direito, que este autor estudou nos seus ensaios, Estudos de Filosofia e Ciência do Direito, Direito Natural/Direito Positivo e Experiência e Cultura. Logo após, é abordado o problema da norma jurídica sob diversos aspectos.

Finaliza com a questão da utilidade do Tridimensionalismo para a análise de qualquer atividade cultural e dá exemplos tomados da prática do Direito. Finalmente comunica o lançamento de sua nova obra Nova fase do Direito Modemo, na qual procura abordar mais amplamente a problemática da Justiça.

\section{Abstract:}

The article begins by treating of the sources that have in - ed the Three-Dimensional Theory of Law, of the versions of the Italian masters Icilio Vanni, Giorgio Del Vecchio and Adolfo Nová and the question that came from the benches of Academia on the essential problem relating to the structure of juridical experience, of the need to go beyond a methodological discrimination to arrive at the juridical reality itself.

* Reconstrução da "aula" dada por ocasião da homenagem que me foi prestada pela Faculdade de Direito da Universidade do Estado do Rio de Janeiro, a 25 de março de 1992, quando Antonio Paim, Ubiratan de Macedo e Aquiles Cortes Guimarães apreciaram distintos aspectos de minha atividade intelectual. 
It criticizes then the kelsinian view of Law, conceived as a simple rule, besides a short history of the evolution of the notion of a Three-Dimensional Structure and of the dialectics of the three elements and the consequences: fact - value - rule; rule value fact; rule fact value.

It broaches next the themes of the influence of the phenomenology of Husserl and the question of Lebenswelt in his thought, of the existential dialectics of Law, that this author studied in his essays, Studies in the Philosophy and Science of Law, Natural Law/Positive Law and Experience and Culture. It treats after that of the problem of juridical rule under several aspects.

The article ends with the question of the use of ThreeDimensionalism for the analysis of any cultural activity and gives examples from the practice of Law. It finishes by communicating the publishing of his new work $A$ new phase of Modem Law, in which he tries to treat more extensively of the problems of Justice.

Em homenagem aos estudantes, que tão gentilmente vieram ouvirme, vou fazer de conta que estou na Faculdade de Direito de São Paulo e dizer, de certa maneira, o que é o tridimensionalismo jurídico, recordando os seus momentos fundamentais, até a sua compreensão atual em termos de modelos jurídicos, estabelecidos em função das mutações operadas no "mundo da vida comum" (Lebenswelt).

A Teoria Tridimensional do Direito foi uma intuição da juventude. Intrigou-me o fato de grandes filósofos do direito italiano coincidirem na divisão da Filosofia do Direito, para fins pedagógicos, em três partes: uma destinada à teoria dos fenômenos jurídicos; outra cuidando dos interesses e valores que atuam na experiência jurídica e, finalmente, uma terceira relativa à teoria da norma jurídica. O primeiro a dar-nos essa divisão tripartida foi Icilio Vanni, o qual, como positivista-crítico que era, dava mais importância ao que ele chamava Fenomenologia Jurídica, por dizer respeito ao Direito como fato social, completando-a com a Gnoseologia Jurídica, pertinente à norma, e a Deontologia Jurídica, relativa aos deveres jurídicos. Del Vecchio, seu discípulo, sendo neokantiano, manteve a tripartição, mas sob outro prisma: teoria da idéia do Direito ou Justiça (Deontologia Jurídica); teoria do conceito de Direito ou Gnoseologia Jurídica, reservando poucas páginas à Fenomenologia Jurídica. Já 
Adolfo Ravà dava ênfase à norma jurídica como norma técnica, completando-a com as outras duas partes.

Pois bem, minha pergunta foi esta: no fundo dessa divisão pedagógica, não se esconde um problema essencial quanto à estrutura da experiência jurídica? Não é necessário ir além de uma discriminação metodológica para se alcançar a realidade jurídica em si?

Foi essa pergunta, nascida nos bancos acadêmicos de minha Faculdade, que ficou provocando meu subconsciente durante muito tempo. Em 1933, tive, pois, uma pálida idéia, uma intuição, do tridimensionalismo, mas foi só em 1940 que, na realidade, pensei que o Direito não podia ser concebido à maneira de Kelsen, como uma simples norma. Então, eu tive a ousadia de me contrapor ao maior jurista do nosso século que é sem dúvida Hans Kelsen, a tal ponto que eu costumo dizer que ele representa o meridiano de Greenwich da Jurisprudência. Ocupa-se uma posição no espaço jurídico conforme se está mais perto ou mais longe de Kelsen. Isto se deu em minha tese de concurso à cátedra de Filosofia do Direito, intitulada Fundamentos do Direito.

Kelsen estava, em 1940, no esplendor de sua primeira fase, porque ele tem três fases. Kelsen foi um jurista que mudou muito ao longo do tempo. Em 1940 ele era conhecido sobretudo como o jurista da norma, do normativismo hierárquico, da pirâmide da norma jurídica, conforme expunha em sua Teoria Pura do Direito (1 $1^{a}$ edição).

Se se perguntasse a Kelsen o que é Direito, Kelsen responderia: "Direito é norma jurídica e não é nada mais do que norma". Muito bem, eu preferi dizer: "não, a norma jurídica é a indicação de um caminho, porém, para percorrer um caminho, eu devo partir de determinado ponto e ser guiado por certa direção: $o$ ponto de partida da norma é o fato, rumo a determinado valor". Desse modo, pela primeira vez, em meu livro Fundamentos do Direito eu comecei a elaborar a tridimensionalidade. Direito não é só norma, como quer Kelsen, Direito não é só fato como rezam os marxistas ou os economistas do Direito, porque o Direito não é economia. Direito não é produção econômica, mas envolve a produção econômica e nela interfere; o Direito não é principalmente valor, como pensam os adeptos do Direito Natural tomista, por exemplo, porque o Direito ao mesmo tempo é norma, é fato e é valor. E, pela primeira vez, na introdução do livro Teoria do Direito e do Estado, disse aquilo que generosamente um dos maiores 
discípulos de Kelsen, Josef Kunz, qualificou de "fórmula realeana": "o Direito é uma integração normativa de fatos segundo valores"

Essa é a fórmula que Josef Kunz chamou de fórmula realeana. O Direito, repito, é uma integração normativa de fatos segundo valores.

Isso ocorreu em 1940, e esta idéia continuou me apaixonando, porque, meus amigos estudantes, o homem de ciência tem que ter uma curiosidade infinita. Platão disse e Aristóteles repetiu que a Filosofia e a Ciência nascem da curiosidade, da perplexidade diante da realidade e do desejo de perquirir. A ciência nasce da vaidade e da curiosidade; e como o homem e a mulher somos todos curiosos, não há razão nenhuma para dizer que a mulher seja inferior ao homem em termos de ciência. Porque ela talvez seja até mais curiosa do que o próprio homem... Mas, voltemos à nossa exposição.

A noção da estrutura tridimensional continuou atuando na minha consciência, no meu espírito até que, em 1952, outra intuição apareceu na minha experiência de pesquisador incansável. Essa idéia foi a dialeticidade dos três elementos. Esses três elementos não se correlacionam apenas, eles se dialetizam. Há uma dinamicidade integrante e convergente entre esses três fatores, de tal maneira que nós temos três ordens de dialética, conforme o seu sentido dominante, da seguinte maneira:

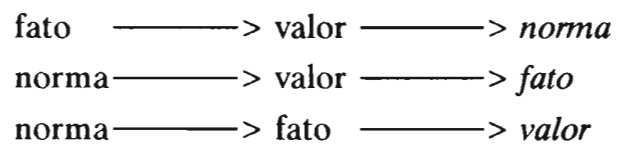

Analisemos cada uma dessas expressões ou enunciados direcionais.

No primeiro caso, visa-se atingir a norma, para interpretá-la e aplicá-la, e temos a Dogmática Jurídica, ou a Jurisprudência (sentido clássico dessa palavra, equivalente a "Ciência do Direito") Positiva. Donde se conclui que, nesse caso, estamos perante a dialeticidade do Direito enquanto este é cultivado pela Ciência do Direito, pela Dogmática Jurídica. Dogmática Jurídica é uma palavra que devemos conservar. Não devemos aceitar a intrujice de dizer que Dogmática Jurídica é a teoria do crê ou morre... Dogma aí não significa verdade que não se discute, mas significa apenas o Direito posto. Nós, os juristas, os advogados, temos que obedecer ao direito posto, porque senão perdemos a causa. Imaginem que um advogado vá ao foro e resolva dizer que é contra o 
Código Civil. O Código Civil é um dogma para o advogado. A Dogmática Jurídica é a teoria positiva do Direito Positivo. Temos assim, portanto, a Jurisprudência, no sentido clássico da palavra, Ciência do Direito.

Note-se que, quando emprego o termo Dogmática Jurídica, a palavra "dogma" não significa, absolutamente, "algo que é imposto", mas tãosomente "algo que é posto".

Porém, o Direito também pode ir da norma para o valor e ao fato. Quem é que estuda o fato segundo a norma valorada? É a Sociologia Jurídica. A Sociologia Jurídica tem como objeto o fato. Nós juristas objetivamos a norma. Nós juristas raciocinamos em termos de normatividade. A norma é o nosso ponto de chegada. Ela é o elemento preferencial da pesquisa do jurista. Mas o sociólogo do Direito, que é que ele quer? Quer conhecer o Direito como fato social. Ora, este fato que não é um fato qualquer, é um fato jurídico. O fato jurídico não se compreende sem referir-se a uma norma e ao valor que se visa realizar. Então, elaborei uma imagem: o Direito não é um queijo ou um doce, se preferirem, com três sabores diversos, correspondentes a três pedaços distintos, de tal maneira que o jurista vem e come a norma, o sociólogo vem e se contenta com o fato, e o filósofo jusnaturalista se perde no mundo do valor.

O Direito é uma realidade, digamos assim, trivalente, ou por outras palavras, tridimensional. Ele tem três sabores que não podem ser separados um dos outros. O Direito é sempre fato, valor e norma, para quem quer que o estude, havendo apenas variação no ângulo ou prisma de pesquisa. A diferença é, pois, de ordem metodológica, segundo o alvo que se tenha em vista atingir. É o que com acume Aristóteles chamava de "diferença específica", de tal modo que o discurso do jurista vai do fato ao valor e culmina na norma; o discurso do sociólogo vai da norma para o valor e culmina no fato, e, finalmente, nós podemos ir do fato à norma culminando no valor, que é sempre uma modalidade do valor do justo, objeto próprio da Filosofia do Direito.

Assim sendo, há três ordens de estudos distintos, mas estudos correlatos, conforme o seguinte quadro direcional:

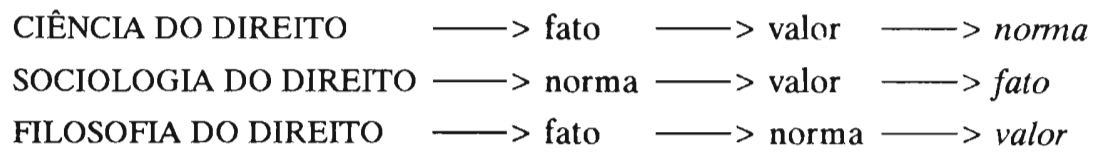


Posso confidenciar aos senhores que foi em 1952 que a Teoria Tridimensional tornou-se madura com a dialetização dos três fatores. Quando se tem 81 anos de idade, a gente tem o direito de ser vaidoso. Eu sou vaidoso por esse ponto de vista dialético. Lembro-me que, em 1952, quando expus esse meu pensamento a um dos maiores filósofos do Direito da Itália, que viera lecionar em São Paulo, o professor Luigi Bagolini, ele com o seu generoso temperamento itálico, exclamou: "Ma è formidabile!" Claro que fiquei contente com essa generosa apreciação de Bagolini, o qual, quatro anos depois, verteu para o italiano minha Filosofia do Direito, publicada no Brasil em 1953. Essa é, portanto, a minha maior vaidade. A vaidade de ter sido fiel a uma intuição da juventude $\mathrm{e}$ ir levando adiante essa cogitação.

Pois bem, em 1968, data lembrada muito oportunamente por Ubiratan de Macedo, eu escrevi duas obras geminadas, isto é, pensadas em conjunto ou geminadamente. Uma se denomina $O$ Direito como Experiência e a outra Teoria Tridimensional do Direito. Que é que eu trago de novo com essas obras?

O que há nelas de novo é uma ampliação do conceito de dialética que já era dialética de complementaridade inserindo-a na experiência jurídica graças ao conceito de Lebenswelt ou mundo da vida, recebido da Filosofia fenomenológica de Husserl, e já objeto de estudo por parte de Dilthey, o mestre da Filosofia dos valores.

Correlacionando os estudos de Husserl, tão justamente admirados por nosso companheiro Aquiles Cortes Guimarães, com os estudos do grande jusfilósofo italiano Giuseppe Capograssi sobre a experiência jurídica, apresento a experiência jurídica sob o prisma tridimensional, aplicando a dialética de complementaridade desde as formas primitivas ou larvares da realidade jurídica, a qual está sempre inserida na globalidade da Lebenswelt ou mundo da vida comum. Destarte, eu dava ao pensamento de Husserl um sentido dialético, que ele não tinha, a partir da idéia de que, se o ser do homem é o seu dever-ser, ele é radicalmente um ser histórico. Esse sentido de historicidade conferido à fenomenologia foi novidade na época, provocando a repulsa de um professor gaúcho, que deve ter ficado muito desapontado quando, poucos anos depois, surgia uma obra póstuma de Husserl inserindo a fenomenologia no processo da história... 
Disse que tomei mais profundo contato com a fenomenologia de Husserl, no que compartilho com o meu amigo Aquiles, mas vale a pena fazer um reparo, fazendo uma recomendação à juventude: não se deixem levar pelos modismos filosóficos. Eu não cheguei a Husserl por ele estar na moda, mas porque ele respondia a uma série de problemas, a uma série de indagações que estavam no meu espírito. Impressionou-me sobretudo a idéia de Lebenswelt, que Husserl desenvolve sobretudo em sua obra póstuma Crise da Ciência Européia e Filosofia Fenomenológica, mostrando que todos nós sentimos, pensamos e agimos inseridos num complexo de noções e opiniões operantes, que ele denominou "mundo da vida". Eu, que estou falando, vocês que me ouvem; o cientista que cuida de pesquisas objetivas; os pais e os filhos; o artista e os admiradores de seus quadros, todos estamos imersos nesse mundo de opinióes que os filósofos ingleses chamavam common sense, no século XVIII, e que pode ser apresentado como um antecedente remoto da Lebenswelt.

Então o Direito não é um fato que plana na abstração, ou seja, solto no espaço e no tempo, porque também está imerso na vida humana, que é um complexo de sentimentos e estimativas. $O$ Direito é uma dimensão da vida humana. $O$ Direito acontece no seio da vida humana. $O$ Direito é algo que está no processo existencial do indivíduo e da coletividade. E assim surgiu uma outra dialética, a dialética existencial do Direito que eu continuei a estudar em ensaios posteriores, como os reunidos em meus livros Estudos de Filosofia e Ciência do Direito, Direito Natural/Direito Positivo e sobretudo em Experiência e Cultura, que é minha obra fundamental.

Aqui, eu peço licença a vocês para mostrar uma outra expressão dialética num jogo de perspectivas, que vou expressar com o seguinte símbolo:

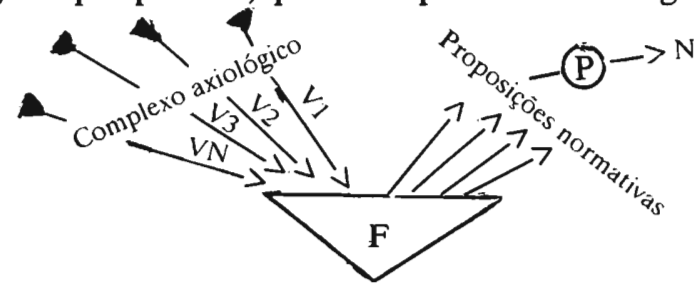

Nomogenese jurídica

Com essa figura, eu quero dizer que, o mundo jurídico é formado de contínuas "intenções de valor" que incidem sobre uma "base de fato", 
refrangendo-se em várias proposições ou direções normativas, uma das quais se converte em norma jurídica em virtude da interferência do Poder.

A meu ver, pois, não surge a norma jurídica espontaneamente dos fatos e dos valores, como pretendem alguns sociólogos, porque ela não pode prescindir da apreciação da autoridade (lato sensu) que decide de sua conveniência e oportunidade, elegendo e consagrando (através da sanção) uma das vias normativas possíveis. Todos os projetos de lei, em suma, em debate no Congresso, para dar um exemplo - perdem sua razão de ser quando um deles se converte em norma legal.

Essa compreensão da gênese da norma jurídica graças à participação do Poder num complexo factual-axiológico (onde, pois, não impera a vontade nua e arbitrária) é outra das contribuições contidas nas duas últimas obras citadas. Note-se que, quando falo em Poder, não penso apenas no Poder governamental, pois, através de sucessivas decisões homogêneas, o Poder Judiciário edita normas jurisprudenciais (Ex: as súmulas do Supremo Tribunal Federal) assim como o Poder social anônimo consagra normas costumeiras ou consuetudinárias. Há ainda o Poder negocial que dá vida aos contratos.

Que é uma norma? Uma norma jurídica é a integração de algo da realidade social numa estrutura regulativa obrigatória. Vamos examinar, por exemplo, o fato econômico, pois qualquer fato pode ser tomado como referencial. Sobre esse fato incide um complexo de interesses ou valorizações que exigem uma disciplina normativa, e edição, por exemplo, de uma norma legal.

Notem que o tridimensionalismo não serve só para o Direito, mas para qualquer atividade cultural. Assim é que o artista, inspirado ante certa realidade factual, projeta a sua preferência valorativa, impressionista ou expressionista, por exemplo, e esta se concretiza numa forma expressa por uma pintura ou uma escultura. O que é uma obra de arte senão a expressão formal de uma vivência axiológica do fato vivido pelo artista? Ora, o que é forma para o artista é norma para o jurista. A norma é a forma que o jurista usa para expressar o que deve ou não deve ser feito para a realização de um valor ou impedir a ocorrência de um desvalor.

Mas acontece que a norma jurídica está imersa no mundo da vida, ou seja, na nossa vivência cotidiana, no nosso ordinário modo de ver e de 
apreciar as coisas. $E$ o mundo da vida muda. Então acontece uma coisa que é muito importante e surpreendente: uma norma jurídica, sem sofrer qualquer mudança gráfica, uma norma do Código Civil ou do Código Comercial, sem ter alteração alguma de uma vírgula, passa a significar outra coisa. Querem um exemplo? Há um artigo do Código Civil (eu não saberia dizer o número, mas se algum civilista aqui presente o souber que me ajude) que declara que a multa convencionada no contrato deve ser paga proporcionalmente ao adimplemento da avença. Pois bem, na época de individualismo que se seguiu ao Código Civil de 1916 até a década de 30, que faziam os advogados? Os advogados são uns seres muito espertos, dotados de esperteza da técnica que é fundamental. Os advogados punham no contrato: a multa será sempre devida por inteiro, qualquer que seja o tempo do contrato. De maneira que aconteceu um caso muito importante em São Paulo, quando uma pobre costureira, que havia cumprido o contrato até o $20^{\circ}$ mês na compra de uma máquina de costura, não pôde mais pagar e o credor exigia, além da devolução da máquina, mais a multa por inteiro. Ora, pela primeira vez na história do Direito brasileiro o Tribunal de Justiça de São Paulo declarou: "Alto lá! O contrato não pode prevalecer sobre a lei e a ressalva contratual é nula de pleno direito". Até então não havia sido posta em dúvida a cláusula contratual, por entender-se que o artigo do Código Civil era apenas dispositivo. O Tribunal de São Paulo, ao contrário, entendeu, e entendeu bem, que essa norma legal era de ordem pública, dirigida ao juiz para um juízo de eqüidade. Além disso, determinou que o bem fosse avaliado, cabendo à costureira parte do valor apurado, o que a lei veio depois consagrar.

Que acontecera? Acontecera que o individualismo anterior cedera lugar a suma compreensão social e humanística do Direito, de tal modo que, em virtude dessa nova ética valorativa, o artigo da lei, sem alteração de uma vírgula, passou a significar algo de diverso, em consonância com os princípios de eqüidade.

Não é demais lembrar que essas alterações do alcance e significado das normas jurídicas é objeto, hoje, de estudos especiais de Semântica Jurídica, uma das partes da Lógica Jurídica, que não é mais apenas a Lógica dos silogismos, o que demonstra que as variações operadas na vida jurídica dão nascimento a novos ramos do saber jurídico. 
Eu costumo representar o processo de variação semântica do Direito com o seguinte gráfico:

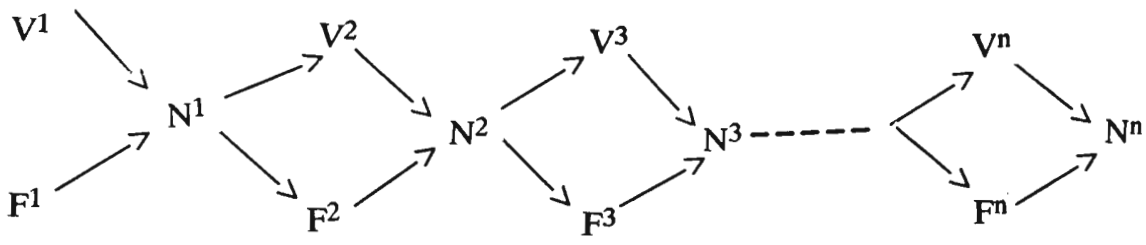

\section{Processo do normativismo concreto}

Vamos dar, agora, um exemplo de mudança do significado do Direito em virtude de alteração no plano dos fatos.

Mas, vou contar-lhes uma aventura que eu tive como advogado, porque eu preciso dizer aos senhores: jamais deixei de ser advogado militante. Só mesmo quando impedido como Secretário de Justiça, ou quando Reitor da USP, porque não dispunha de tempo. Ora, o fato de ser sempre advogado me ajudou muito na teoria, porque me trouxe a experiência, a força do fato social vivido diretamente.

Eu tive um fato muito curioso. Havia em São Paulo, uma grande casa de modas, chamada Casa Vogue, que era digamos assim, o esplendor da moda feminina. A Casa Vogue cresceu muito, cresceu tanto que o dono da casa, que era meu cliente, resolveu derrubar uma parede para aumentar a sua oficina. Sabendo disso, o locador entrou na mesma hora com uma ação de despejo, porque havia uma cláusula no contrato que proibia alterações no imóvel locado. $O$ inquilino me procurou porque ia perder a oficina no coração de São Paulo. Aceitando a causa, procurei no Código Civil um artigo, segundo o qual os tapumes, as paredes divisórias de madeira, podem ser removidos livremente pelo locatário. Então eu disse ao Tribunal de São Paulo mais ou menos o seguinte: "Ilustres Desembargadores, o que houve foi uma mudança essencial no plano dos fatos. O Código Civil Brasileiro foi feito numa época em que as paredes sustentavam edificios, mas, hoje em dia, quando os edifícios têm estrutura metálica, ou de cimento armado, as paredes internas são removiveis como se fossem tapumes, não afetam a estrutura do edifício. Quando o inquilino sair, no término do contrato, ele reporá a parede no lugar." Eu ganhei a causa e ganhei mais experiência jurídica. 
Mas a norma não é também uma coisa assim, que se puxe para lá e para cá. Pontes de Miranda dizia, sabiamente, que a norma jurídica tem certa elasticidade. A norma é elástica. Mas chega um certo momento em que a elasticidade se parte e a norma se rompe. Logo as variações na interpretação da norma devem ser compatíveis com sua elasticidade. Pois bem, quando uma norma deixa de corresponder às necessidades da vida, ela deve ser revogada, para nova solução normativa adequada, o que nos revela a riqueza das soluções que a vida jurídica apresenta.

Quanto mais os senhores estudarem o Direito, mais sentirão a sua beleza. É preciso saber amar aquilo que se pratica com convicção. $O$ jurista que não ama a sua profissão é apenas um "arremedo" de jurista e não merece a mínima atenção.

E agora meus amigos, para terminar, pois o tempo já vai longe, eu acabo de publicar, para comemorar os meus 80 anos, o livro Nova fase do Direito Moderno. E pela primeira vez, notem bem isso meus caros colegas, eu tive a coragem de abordar mais amplamente a problemática da Justiça. Referia-me muito à Justiça, mas nunca tinha escrito de maneira direta sobre ela, examinando-a em profundidade. Talvez eu achasse que ainda não tinha tempo ou conhecimento bastante para escrever sobre a Justiça. E deixei para o meu último livro, o que é um sinal de prudência. Creio que fiz bem, porque ao jurista nunca é demais agir com prudência. Aliás, o nome antigo e clássico de Ciência do Direito era Jurisprudência, palavra que deve ser conservada também em seu sentido pleno, ao lado da subordinada jurisprudência dos tribunais.

Pois bem, em meu último livro, eu desenvolvo o entendimento, ao qual se refere Ubiratan de Macedo, de que a justiça é um valor franciscano. São Francisco, o maior santo da Igreja, ensinava que a razão do amor aos homens culminava no espontâneo ato de dar, de ir ao encontro do outro para ajudá-lo.

Isto posto, entendo que a justiça não é um valor que tenha um fim em si mesma: é um valor supremo, cuja valia consiste em permitir que todos os valores valham, numa harmonia coerente de idéias e de atitudes.

Em verdade, sem base de justiça não pode haver ordem, nem segurança, assim como a riqueza passa a ser privilégio de alguns. $O$ uso da força só é legítimo quando se funda em razões de justiça. 
É por isso que, após Nova Fase do Direito Moderno, cheguei a uma definição do Direito, que pela primeira vez eu vou enunciar como homenagem aos jovens que me ouvem: "O Direito é a concretizaçāo da idéia de justiça na pluridiversidade de seu dever-ser histórico, tendo a pessoa como fonte de todos os valores". 